\title{
The Dictatorship Game: Simulating a Transition to Democracy
}

Luis F. Jiménez, University of Massachusetts, Boston

ABSTRACT A central topic in the comparative-politics subdiscipline is the study of democratic transitions. Despite a growing role-playing literature, there are currently no simulations that illustrate the dynamics of democratic transitions. This article proposes a role-playing simulation that demonstrates to students why it is difficult for countries to transition to democracy and why protests are a necessary but not sufficient condition to topple a dictatorship. As surveys and teaching evaluations subsequently showed, this exercise succeeded in clarifying the more difficult theoretical concepts as well as in making a potentially dry subject more accessible.

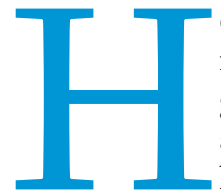
ow does an instructor illustrate the dynamics involved in democratic transitions in an undergraduate course? Oddly, although the role-playingsimulations literature has expanded rapidly, little has been written on the specifics of transitions to democracy, which is a central topic within the comparative subdiscipline. For instance, the literature includes numerous simulations in comparative politics that encompass a multitude of settings, such as the formation of parliamentary coalitions, negotiations between local leaders and the central government in Russia, and ethnic-group negotiations in Sub-Saharan Africa (Biziouras 2013; Marsh and Bucy 2002; Shellman 2001; Stover 2005; Switky 2004). Some simulations explicitly attempt to illustrate key theories in the American- and comparative-politics subfields (Smith 2012); however, I am unaware of any that specifically consider the underlying mechanisms of democratic transitions. This paper attempts to rectify this situation.

The comparative-politics literature includes numerous classical works on democratization and regime change (e.g., Linz and Stepan 1978, 1996; O'Donnell, Schmitter, and Whitehead 1986). This simulation, however, is modeled after Booth, Wade, and Walker's (2006, 32) theory of regime change, a useful theoretical summary of the dynamics of democratic transitions: "[an authoritarian] regime experiences a crisis when [their coalition] forces (1) undermine the loyalty and cooperation of some or all of the coalition members, (2) undermine the resource base and capacity of the regime to respond to challengers, or (3) mobilize external actors against the regime." These points serve as the explanatory basis

Luis F. Jiménez is an assistant professor of political science at the University of

Massachusetts, Boston. He can be reached at luis.jimenez@umb.edu. for the simulation, which is structured so that the dictatorship cannot fall unless the coalition members choose to opt out or the regime can no longer respond effectively to challengers. The basis further rested on Booth, Wade, and Walker's claim of potential political outcomes in the face of a rebellion or revolution. As they stated: "The settlement upon a new regime will derive from the eventual resolution of forces among the various political actors. A single regime shift may not bring enough change to permit political stability...If important actors...remain unsatisfied or unsuccessfully repressed, the new regime may be unstable" (Booth, Wade, and Walker 2006, 33). This latter point, in particular, shows the difficulty in achieving stability for a regime, not to mention democratization.

Given these considerations, the simulation design contained three learning objectives: (1) why certain timing and environments are more conducive to protests, (2) why protests are a necessary but not sufficient condition in the toppling of an autocracy, and (3) why the same circumstances that made it possible to oust a particular dictator often are detrimental in the formation of a state that is both functioning and relatively democratic.

\section{THE SIMULATION SETUP}

This simulation has been a part of my course titled Comparative Politics of Transitional Societies on five separate occasions. Given the diverse nature of the student body at the university where I teach-an urban commuter campus and the only public school in the city of Boston-virtually every type of student has participated in the exercise. This is because the class can be used to meet our major's requisites as well as fulfill generaleducation requirements. Therefore, the share of non-majors oscillated between $64.5 \%$ and $87.5 \%$ but never less than the former 
percentage. Table 1 is a comparative summary for students in the class and the larger university.

I first explained the nature of the simulation in the syllabus and at the beginning of the course and then asked for volunteers to play various roles, which I assigned randomly. I gave the players their prepared bio and asked them to review it before the next class session. I also asked the would-be dictator to choose a name-an "official" name encourages creativity even before the simulation begins. I have used different variations in the total number of students I ask to participate, ranging from 10 to 20. Ultimately, I find that 15 works best-too many more and it becomes unwieldy, fewer and the simulation might not last as long as intended-although this is entirely dependent on class enrollment. However, regardless of the number of participants and to prevent unnecessary complication, I do not include more
Specifically, I ensured that the dictator mastered two key points of the game: (1) every single decision would net or lose points, and (2) there was a particular point at which the dictator could be ousted-however, that point would not be known. This latter detail strove to mimic the uncertainty that authoritarian regimes face because a priori it is impossible to know the precise limit of their authority. Judicious dictators would be sure to closely track their potential toppling point and act accordingly-which adds an interesting layer to the game because it can dramatically alter dictatorial responses, often precipitating unexpected denouements.

I then introduced the ground rules of the game, particularly the choices each player would confront and the potential consequences they would face. Civilians moved first; however, the game continued to revolve around the dictator, who at each instance could select from three distinct possibilities: (1) respond

\section{A rational autocrat would realize that co-optation is an astute strategy because it would guar- antee that no one joined the individual rebel, thereby ensuring that as few points as possible were lost.}

than the 15 bios described in the online appendix. If an instructor wants to include 20 or more students, I recommend simply duplicating the number that represents the masses as necessary. At this stage, it is crucial to emphasize that participants cannot share their profile details with anyone else, particularly the specific points that the dictator might stand to gain or lose depending on his or her behavior. In fact, because the simulation assumes that coordination costs result only from rebelling, at no point can players coordinate with one another. In addition, it must be reiterated that whereas players are free to determine their responses as the game unfolds, they must do so as close as possible to the profile to which they were assigned.

On the day of the simulation, before giving the specific scenario to the entire class, I reemphasized to the participants that they could not talk to one another, gave them a blueprint of how the simulation would develop, and answered any questions. with force, either lethal or in the form of torture; (2) do nothing or (3) attempt to co-opt those who might have revolted. A critical consideration, however, was that if the dictator opted to respond with force to a potential revolt and then that person subsequently was joined by more rebels, the despot would have the opportunity to successfully kill only one of the rebels, potentially leaving increasingly larger demonstrations behind. In other words, force-although effective at times-could and did backfire. A rational autocrat would realize that co-optation is an astute strategy because it would guarantee that no one joined the individual rebel, thereby ensuring that as few points as possible were lost. To prevent this, there are two limits on the power of a dictator to co-opt potential rebels. First, the autocrats may only co-opt someone on three separate occasions without penalty. After that, they can still elect to do so but it will cost them-usually half of the points they would surrender if someone rebelled-however, the

Table 1

\section{Statistical Breakdown for Comparative Politics of the Developing World}

\begin{tabular}{|c|c|c|c|c|c|c|c|c|c|}
\hline & Total & Men & Women & Majors & Non-Majors & Freshmen & Soph. & Juniors & Seniors \\
\hline Fall 2011 & 32 & 22 & 10 & 7 & 25 & 3 & 13 & 5 & 10 \\
\hline Fall 2011 (2) & 33 & 20 & 13 & 8 & 25 & 3 & 6 & 14 & 10 \\
\hline Spring 2011 & 40 & 24 & 16 & 5 & 35 & 10 & 9 & 13 & 8 \\
\hline Fall 2012 & 31 & 15 & 16 & 11 & 20 & 1 & 5 & 15 & 12 \\
\hline Fall 2012 (2) & 27 & 14 & 13 & 9 & 20 & 1 & 5 & 12 & 9 \\
\hline \multirow[t]{2}{*}{ Spring 2014} & 42 & 27 & 15 & 18 & 24 & 4 & 12 & 18 & 8 \\
\hline & 205 & 122 & 83 & 58 & 149 & 22 & 50 & 77 & 57 \\
\hline \multicolumn{10}{|c|}{ Comparison with UMass Boston } \\
\hline & Total & \%Men & \%Women & \multicolumn{3}{|c|}{$\begin{array}{l}\text { \% of African-American Political } \\
\text { Science graduates (2013) }\end{array}$} & \multicolumn{3}{|c|}{$\begin{array}{l}\text { \% of Hispanic Political Science } \\
\text { Graduates (2013) }\end{array}$} \\
\hline $\begin{array}{l}\text { Comparative } \\
\text { Politics Class }\end{array}$ & 205 & 59.5 & 40.5 & & & & & & \\
\hline UMB & 10608 & 44 & 56 & 10.1 & & & 7.6 & & \\
\hline
\end{tabular}


dictator would not necessarily know this. Second, the co-optation is valid for only two rounds of protest. After that, a co-opted individual may opt to join the protests-a point that the instructor should make clear to the players. Thus, as their real-world counterparts have discovered, the co-optation strategy cannot be sustained indefinitely. However shrewd this strategy could have been as an opening gambit, dictators rarely if ever used it more than once. There seemed to be a bias toward repression because players believed that that is what authoritarian regimes are expected to do or because the simulation advanced more rapidly in that direction. Either way, this was a fruitful avenue of inquiry in the debriefing, which well demonstrated the complexities of retaining power.

It was necessary to address two final matters before continuing the simulation. First, someone was needed to monitor the autocrat's score. This was the only person other than the instructor who knew the exact number at which the dictator would be overthrown and, as such, the only one who could announce the despot's demise. The number, chosen by the instructor, is the number of points that the dictator has at the outset. As the game develops, the autocrat will gain or lose points depending on his or her actions; the regime is toppled when the dictator runs out of points. Second, ensuring that the rest of the class will participateeven indirectly-is essential. Although assignments would have rebel-although this was rare, it did happen-I simply moved to another profile. Nevertheless, as described previously, if at any point the autocrat moved to repress one of the participants, the other five players had the prerogative to determine whether they would join in the rebellion. If so, the regime would be able to kill or torture only one of the rebels, thereby losing whatever points the standing protest yielded. To actually quash the protests, however, the dictator had to designate one of the players representing his or her political apparatus to attempt the execution. These participants-the dictator's son, head of the military, head of the party, or young colonel in the military-then would be able to either accept or reject the dictator's orders. A refusal signaled, in effect, that a part of the dictator's inner circle had joined the rebellion's side. This prompted a reset to the dictator's options in which choosing to respond with violence meant they had to again elect someone to carry out the potential execution.

To introduce uncertainty into the outcomes of these conflicts, I used dice; both players had to roll simultaneously to determine whether a rebel had survived. In the event of a tie, the dictator lost. The reason for this was to give a slight advantage to the masses but, equally as important, to reflect the complexity of suppression in which an attack on a protest must leave no remnants behind. After all, any suppression can incur public-opinion costs; however, if a protest survived a display of force, the damage to the regime

\section{The simulations were tailored to reflect the real-life dynamics in democratic transitions, in which protests alone are necessary but not sufficient in dislodging a dictatorship.}

an obvious part in that, ${ }^{1}$ I have found that real-time engagement secures a higher level of retention and understanding in the subsequent discussion. To accomplish this, I divided the class into three groups-foreign leaders, domestic press, and "the people"and asked relevant questions throughout the simulation. I invited the groups to make predictions as the game developed: Was the dictator being sincere? Would Player X rebel or pass on the opportunity? Most important, however, I instructed them to analyze the effectiveness of the various players' decision making. ${ }^{2}$ Another way to maintain the students' attention is to create protest signs. A few may be distributed before the simulation begins for display at their discretion. The signs can be as complex or as simple as the instructor prefers (e.g., "Power to the People" and "We Want Change Now").

\section{THE ACTUAL SIMULATION}

Once these parameters were established, I explained the scenario described in the online appendix, which details Bostonia as a brutal dictatorship. I then asked one of the least politicized profilesthe young housewife, the taxi driver, the small-business owner, the nun, the unemployed lawyer, or the female street vendor-to move first. That is, they introduced their own character's sketch and then I related it back to the larger saga, as described in the appendix. If students are shy or hesitant, the instructor may read it or allow them to summarize it.

At this point, the interaction between the dictator and the players commenced. The original player could opt to rebel or not; if the former, the regime could respond with violence, co-optation, or silence. If the student opening the game selected not to would increase because the public at large can attest to the victimization of the survivors. The rolling of the dice occurred every time that one member from the dictator's circle attempted to kill a rebel, whether or not that person was originally a member of the masses. Every roll meant that someone lost; at that point, the student who lost would have to sit down. If one of the rebels won, that meant they were now in standing rebellion, and they would remain in active defiance.

As the simulation progressed, I turned to the profiles representing the masses to test whether they would rebel. If eliminated, participants had to read their profile to the class and announce the specific sum that the autocrat had gained or lost. Consequently, as the situation on the ground shifted, the other players had the power to join the protests at any point. In particular, the exiled opposition leader was a key figure who could disproportionately affect the fate of the revolution and, as such, must always be sensitive as to the best time for his or her return. ${ }^{3}$ This pattern eventually reached a point where either the dictator was overthrown or no one representing the masses was left to protest. The latter outcome was rare and occurred only once in five different exercises. Note, however, that based on various profile points, it is extremely difficult if not impossible for protests alone to succeed in ousting the authoritarian regime. In fact, this outcome did not materialize in any of the simulations. The simulations were tailored to reflect the real-life dynamics in democratic transitions, in which protests alone are necessary but not sufficient in dislodging a dictatorship.

Likewise, and contrary to what some students might expect, the simulation did not end with the dictator's toppling. Rather, the 
successful revolutionaries were required to provide the Bostonian people with a transition plan. To do this, I asked the remaining insurgency members to elect a leader, who then announced the next steps in a formal address to the class. We obviously expected the new leader's transition program to be lacking; if that were the case, I ensured that the new administration answered key questions, such as whether there would be elections, who would be in charge in the interim, and whether there would be any restrictions on the populace. These questions can be expanded or tailored to the specific points that a potential instructor might want to highlight. Given that this part of the simulation was deliberately open-ended, students occasionally improvised and either claimed the power for themselves-both the exiled leader and the head of the military did this when presented with command of the insurgency-or refused to recognize the authority of the newly created government and continued their rebellion. Again, this uncertainty is built into the simulation because it mirrors the instability and confusion that revolutionary transitions tend to exhibit and how political vacuums often lead to unpredictable consequences.
Finally, the open-ended nature of the simulation's transition revealed how the same dynamics that brought about the dictatorship's collapse often prevented the establishment of a stable democracy. This became apparent to students when some of the dictator's former associates retained power; the prevailing response was either to doubt their intentions or predict the emergence of a fresh autocracy. In fact, the class grasped a critical element of democratic transitions: whereas dictatorships are more likely to survive bottom-up revolutions, top-down revolts often simply replace one autocracy with another. Thus, as formidable as it is to bring about the collapse of a dictatorship, it is infinitely more difficult to construct a functioning democracy.

The debriefing also allowed me to assess the students' reactions. The responses to the simulation as it occurred, in subsequent classes, and in teaching evaluations were overwhelmingly positive. I conducted a separate survey that asked about this particular simulation and that sampled all students who had taken the class since 2011. I found that for the majority of students, it was one of the most memorable aspects of the class: after several semesters had elapsed, at least $42 \%$ reported remembering

\section{Likewise, the simulation presented an effective scenario for illustrative purposes that I referred to repeatedly for the remainder of the course.}

\section{THE SIMULATION DEBRIEF}

In general, the length of the simulation was about 45 minutes. A subsequent debriefing averaging 30 minutes further examined and internalized the lessons from the simulation (Asal and Blake 2006). The debriefing concentrated on the learning objectives described at the beginning of the simulation. First, the class considered why individuals initially rebelled. After listing specific grievances of the original players, students began to recognize the role of public space in reducing fear. That is, whereas authoritarianism thrives on fear, compliance cannot be sustained with the accumulation of force alone because the public will always outnumber any potential authority. Rather, it must be a self-policing matter in which the dissenters opt to exit the political arena. This type of protection for the dictatorship begins to vanish as soon as demonstrations are allowed to grow; joining one's neighbor in protest does not constitute the level of danger that starting one's own would, and each additional protester reduces the risk and undermines the regime's propaganda.

Second, the debriefing allowed for probing of the dictator's strategies. Specifically, the students contemplated critical junctures in the dictator's strategy. The student who played the despot frequently outlined a posteriori a more optimal strategyan approach that often emphasized co-optation. The rest of the class also noted the disproportionate influence that the regime higher-ups had on the outcome, and they recognized how divisions within the dictator's inner circle facilitated collective action against the government. That is, they identified that protests alone cannot bring down the government-one of the main learning objectives. Likewise, in the case in which the dictatorship survived, students determined the significance of a mixed strategy on the part of the autocrat and how the establishment of a system in which others are complicit facilitated that survival. it somewhat and $40 \%$ extremely well. Most important, for many students, it provided a core understanding of the dynamics involved in the toppling of a dictatorship. For instance, in the survey, one student raved: "The Dictatorship Game was one of my favorite activities not only in class, but in my entire college career." Another wrote: "I felt that the dictatorship simulation helped me better understand the process that states go through when there are major changes in how their governments operate. For me, it also highlighted the many barriers that states face while transitioning from authoritarian governments to more liberal systems." In all, 77\% described the simulation as very useful or extremely useful in comparison to other class activities and assignments; $22 \%$ found it moderately useful. Most significant, $81 \%$ correctly chose one of the central points of the simulation: it takes more than protests to topple a dictatorship. Likewise, the simulation presented an effective scenario for illustrative purposes that I referred to repeatedly for the remainder of the course.

Nevertheless, despite the effectiveness of the simulation, instructors must continually strive to get students to think abstractly. A drawback from a simulation like this is that students may fixate on the specific permutation that occurred in the classroom and mistake that particular iteration as what occurs in a "normal" transition. Therefore, all of the underlying factors must be constantly and carefully considered and emphasized. In other words, an unstated goal of the simulation is for students to recognize it as a model with general applicability rather than a specific stepby-step guidebook.

\section{CONCLUSION}

An open-ended simulation like the one described in this article is a powerful teaching tool that, when personalizing complex situations, can make distant and inscrutable events appear not only 
interesting but also elucidative of other phenomena. In addition, as a central component of interest in comparative politics, the simulation can serve as a reference point for future discussions and as an acute means to interpret rapidly shifting events across Africa, Asia, and the Middle East. Finally, a simulation can enhance overall satisfaction and therefore retention, which in turn can help students in subsequent courses.

\section{SUPPLEMENTARY MATERIAL}

To view supplementary material for this article, please visit http:// dx.doi.org/S1049096514002108.

\section{NOTES}

1. I ensured that my class paid attention by requiring a paper based on the simulation. For the assignment, students had to consider what they anticipated would happen as a result of the events in the simulation. Will Bostonia remain an autocracy, become a hybrid regime, or turn into a democracy? Their argument had to be based on both specific events from the simulation and assigned readings.

2. An instructor might be tempted to include the entire class in the simulation; however, as previously mentioned, doing so quickly becomes unwieldy with too many characters. Thus, it is best to leave some of the class without direct participation and encourage those students to pay attention with questionsbut most effectively with a specific assignment. Another option is to make the simulation part of the exam, by asking either specific questions about the events or theoretical questions, and then having students respond with particular events from the simulation.

3. Note that the simulation does not consider foreign influence or intervention Although this is included in Booth. Wade, and Walker's (2006) variables, I thought it might create unnecessary complexity-particularly because I wanted to maintain the simulation as grounded as possible in comparative politics. Nonetheless, it could easily be expanded and even used in an international-relations context. The simulation also can be considered in the debriefing section of the exercise.

\section{REFERENCES}

Asal, Victor, and Elizabeth Blake. 2006. "Creating Simulations for Political Science Education." Journal of Political Science Education 2 (1): 1-18.

Biziouras, Nikolaos. 2013. "Midshipmen Form a Coalition Government in Belgium: Lessons from a Role-Playing Simulation." PS: Political Science and Politics 46 (2): 395-9.

Booth, John A., Christine J. Wade, and Thomas W. Walker. 20o6. Understanding Central America: Global Forces, Rebellion and Change. Boulder, CO: Westview Press.

Linz, Juan J., and Alfred Stepan. 1978. The Breakdown of Democratic Regimes. Baltimore: Johns Hopkins University Press.

- 1996. Problems of Democratic Consolidation and Transition: Southern Europe, South America and Communist Europe. Baltimore: Johns Hopkins University Press.

Marsh, Christopher, and James Cole Bucy. 2002. "Negotiating Russian Federalism: A Simulation for Comparative Politics." International Studies Perspective 3 (4): $373-83$.

O’Donnell, Guillermo, Phillipe C. Schmitter, and Lawrence Whitehead, eds,. 1986. Transitions from Authoritarian Rule. Baltimore: Johns Hopkins University Press.

Shellman, Stephen M. 2001. "Active Learning in Comparative Politics: A Mock German Election and Coalition-Formation Simulation." PS: Political Science and Politics 34 (3): 827-34.

Smith, Keith. 2012. "Why Just Two Parties? A Voting Game to Illustrate Duverger's Law." PS: Political Science and Politics 45 (4): 759-64.

Stover, William J. 2005. "Teaching and Learning Empathy: An Interactive Online Diplomatic Simulation of Middle East Conflict." Journal of Political Science Education 1 (3): 207-19.

Switky, Bob. 2004. "Party Strategies and Electoral Systems: Simulating Coalition Governments." PS: Political Science and Politics 37 (4): 101-104. 